\title{
Sciendo
}

Environmental \& Socio-economic Studies

DOI: 10.2478/environ-2019-0016

Environ. Socio.-econ. Stud., 2019, 7, 3: 38-53

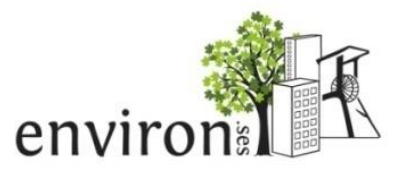

(C) 2019 Copyright by University of Silesia in Katowice

Original article

\section{An assessment of the local empowerment and environmental management programme (LEEMP) for poverty alleviation in Oyo State, Nigeria}

\author{
Ayobami A. Akanmu*1, Umar O. Salisu*2, Simeon O. Fasina², Samuel A. Okunubi \\ ${ }^{1}$ Department of Urban and Regional Planning, The Oke-Ogun Polytechnic, Saki, Nigeria \\ 2Department of Urban and Regional Planning, Olabisi Onabanjo University, Ago-Iwoye, Ogun State, Nigeria \\ ${ }^{3}$ Department of Urban and Regional Planning, Abraham Adesanya Polytechnic, Ijebu Igbo, Ogun State, Nigeria \\ E-mail address (*corresponding authors): ademolakanmu@gmail.com, obafemiumar@gmail.com \\ ORCID iD: A.A. Akanmu://orcid.org/0000-0002-9264-5863; U.O. Salisu: https://orcid.org/0000-0003-1630-3420; S.0. Fasina: \\ https://orcid.org/0000-0003-4989; S.A. Okunubi: https://orcid.org/0000-0003-0496-7537
}

\begin{abstract}
Efforts to liberate the populace, most especially rural communities, from the shackles of poverty, have been ongoing through several approaches since the independent era in Nigeria. The most recent is the Local Empowerment and Environmental Management Programme (LEEMP) which is tailored to undertake projects capable of alleviating poverty. This study assessed the LEEMP projects in Itesiwaju Local Government Area of Oyo State in Nigeria. Data collection methods were through a questionnaire survey and an interview. A random sampling technique was employed to sample 152 residents from the study population of 30,400 and the results were analysed using both descriptive and inferential statistics. A binary logistics regression was used to determine the influence of the LEEMP projects on the socio-economic status of residents. The findings revealed that: LEEMP projects were mostly the initiatives of both the community and LEEMP officials ( $72 \%)$; over $80 \%$ of the respondents observed that community involvement was mainly about land provision and the labour force, justifying over $70 \%$ active involvement of the community in the project execution and maintenance. Inferentially, the prediction model was able to classify $83 \%$ of the cases correctly, indicating that the predictors contribute significantly to prediction power of the logistic regression model $(\mathrm{p}<0.000)$. The Pseudo R-Square of Cox \& Snell's R-square $(28 \%)$ and Nagelkerke's R $(42 \%)$ also show that the model was relevant in predicting the influence of the LEEMP projects on the residents' socio-economic status. However, age $(\mathrm{p}=0.000)$, household size $(\mathrm{p}=0.019)$, average monthly income $(\mathrm{p}=0.033)$, and educational status $(\mathrm{p}=0.038)$ predictors best contributed to the model prediction. The study, however, recommended among others, that the LEEMP projects should be extended extensively within the country accompanied by an injection of adequate funding and a project monitoring mechanism for continuous functionality and sustainability.
\end{abstract}

KEY WORDS: local empowerment and environmental management programme (LEEMP); poverty alleviation; community; residents; Itesiwaju-Oyo State, Nigeria

ARTICLE HISTORY: received 12 February 2019; received in revised form 25 July 2019; accepted 31 July 2019

\section{Introduction}

There are abundant natural resources such as crude oil, tin, gold, limestone, natural gas and a favourable climate in Nigeria with vast arable land to make the country and her inhabitants live in abundant prosperity (ALABI ET AL., 2013). In the face of the abundance of these minerals and human resources, poverty remains one of the greatest challenges facing the country. Although, poverty is an age-long attribute of human existence since natural resources are unevenly distributed across geographical locations, it is a global phenomenon that is relative, complex and multi-dimensional in scope. The WORLD BANK (2006) sees hunger, lack of shelter, ignorance, impoverishment, malnutrition, fear and various forms of deprivation as poverty in simpler forms. 
The National Bureau of Statistics (NBS) (2012) gives the trend of poverty in the country as: $54 \%$ of the populace were living in poverty in $2004,69 \%$ in 2010 and $72 \%$ in 2011, this is despite the $7 \%$ average annual growth of income in the non-oil sector. Comparing this to the World Bank Benchmark of $\$ 1$ per day, nearly three quarters of the Nigerian population are living below $\$ 1$ (\#360) per day. Rural populations are mostly affected by poverty-related incidences in the country. Hitherto, poverty eradication, or alleviation, has been given attention at national level since 1960 by successive administrations.

The recent global efforts were encapsulated in Goal 1 of the Millennium Development Goals (MDGs) which sought to eradicate extreme poverty and hunger by 2015 . Thus, efforts are channeled to reduce by half, the proportion of people living in hunger and extreme poverty in the world by the year 2015 (UNITED NATIONAL DEVELOPEMNET PRogramme UndP, 2006). The Local Empowerment and Environmental Management Programme (LEEMP) as a recent initiative was a means to combat poverty especially in rural areas. According to OJOAWO (2013), LEEMP became effective in August 4, 2004 and November, 2009 in nine pilot states in Nigeria. The states were Adamawa, Bauchi, Bayelsa, Benue, Imo, Enugu, Kastina, Niger and Oyo State. The programme was initiated with the aim of enhancing the standards of living of the rural dwellers towards empowering local communities in managing their environmental resources for optimum development. However, after almost a decade since the introduction of LEEMP in these states, it has become expedient to assess the effectivenesss of the programme, and appraise LEEMP projects in Itesiwaju Local Government Area of Oyo state.

Based on this backdrop, this study aimed to appraise the impacts of the projects executed under the Local Empowerment and Environmental Management Programme (LEEMP) in the study area so as to determine its influence on the standards of living of the benefiting communities. Hence, these aims were pursued:

i. To examine the socio-economic attributes of residents of Itesiwaju LGA, Oyo State as a beneficiary of LEEMP projects

ii. To identify the executed LEEMP projects in the study area

iii. To identify the shortcomings associated with executed LEEMP projects and environmental challenges in the study area

iv. To examine the effectiveness of the executed LEEMP projects in Itesiwaju Local Government Area of Oyo State v. To appraise the involvement and support of the community on LEEMP project development and maintenance

vi. To determine the extent of the existence of LEEMP projects on the socio-economic attributes of residents.

\section{Conceptual underpinning and brief literature review}

2.1. Concept of Millennium Development Goals (MDGs) and Community-Driven Development

The concept of MDGs was derived from development targets of world leaders and adopted as the United Nations Millennium Declaration which was the main outcome of the Millennium Summit in the year 2000. According to ANDY \& ANDREW (2004), the MDGs originated from the United Nations Millennium Declaration which asserted that every individual has the right to dignity, freedom, equality and a basic standard of living (that includes freedom from hunger and violence and encourages tolerance and solidarity). The MDGs was formulated following the Millennium Summit of the United Nations in 2000.

According to ALABI ET AL. (2013), the goals consist of the eradication of extreme poverty and hunger, achieving universal primary education, promoting gender equality and empowering women, reducing child mortality rate, improving maternal health, combating HIV/AIDS, malaria and other diseases; as well as ensuring environmental sustainability and developing a global partnership for development. Thus, the MDGs set concrete targets and indicators for poverty reduction in order to achieve the rights established in the Declaration. However, eradicating extreme poverty continues to be one of the main challenges of the present time. It is in view of this that the MDGs set time-bound targets, by which progress in reducing income poverty, hunger, disease, lack of adequate shelter, while promoting gender equality, health, education and environmental sustainability can be measured. According to KIMooN (2010), the MDGs are the comprehensive United Nations development agenda that set the course for the world's efforts to alleviate extreme poverty by 2030 .

Also, the Concept of Community-Driven Development (CDD) was developed by the World Bank as a result of the failure of the previously embraced Top-Down approach to address inequality and development gaps (ONAH ET AL,, 2013). For instance, LIMAN \& NGAH (2015) opine that the effective incorporation of rural communities 
into the management of rural development projects requires full community participation in the development process. This is aside from requiring collective action which ties the community into values, sustainable maintenance of infrastructure and improvements in the culture of environmental conservation among others. Thus, infrastructure deterioration in rural communities in developing countries could be improved when the beneficiaries participated in the development process.

CDD is a qualitative participation which is referred to as a process of controlling decisions and resources by community-based groups for participatory improvement of natural, physical and social infrastructure. It gives control of development decisions and resources to community groups in which poor communities receive funds, decide on their use, plan and execute chosen local projects and monitor the provision of services that result from such projects. As a result, the World Bank and other donors do dedicate sizeable portions of their portfolios to Community-Driven Development (CDD) projects. Accordingly, over 9 percent of the World Bank total lending support was for CDD projects denoting a magnitude of investment in billions of dollars (CASEY ET AL., 2013).

It is in this vein that the Federal Government of Nigeria in conjunction with the World Bank designed the LEEMP to address the problems of poor management and unsustainable environmental situations, poor utilization of non-replenishable cultural resources, extreme rural and urban poverty and highly centralized governance.

\subsection{Brief literature review}

ALABI ET AL., (2013) observe that poverty is not only a relative term, but also an age-long attribute of human existence as resources are unevenly distributed across geographical locations. UNDP (2006) opines that, food is the fundamental basic need of man as hunger and malnutrition are the most fundamental ingredients of poverty as 1.2 billion people are hungry across the world. OLUDIMU \& TIJANI (2009) corroborated this assertion that, 1.02 billion people in the world are undernourished as a result of the continuous rise in food prices; hence the eradication of extreme poverty and hunger is primarily the most expedient and first basic target of the MDGs.

As demand for food products is rising with more than 28 million new births globally, OLORUNFEMI \& ASHAOLU (2009) are of the opinion that the number of undernourished people in the world is estimated to be 852 million of which $96 \%$ (815 million) are from developing countries including Nigeria. With this, poverty is seen as a state of malnutrition and total lack of access to services and resources. Poverty, according to OGUNLEYE (2006), is a global phenomenon that is dynamic, complex and multi-dimensional; hence it is beyond socio-economic, physical and political administration and it reduces the value of living of people in a given society.

The WORLD BANK (2006) uses income to define poverty from a global perception that of a 6 billion world population, almost $50 \%$ live on less than $\$ 2$ per day, while one-fifth (1.2 billion) live on less than $\$ 1$ per day. It is estimated that $44 \%$ live in South Asia and 24.3\% are in Sub-Sahara Africa. Hence, those living on less than \$1 per day are widely accepted as poor, and used as a benchmark for extreme poverty. Despite several poverty alleviation programmes in Nigeria, WORLD BANK (2006) still posit that over $70 \%$ of Nigerians are still vegetating below the poverty line, while the problem of poverty continues to increase daily in every sphere of the nation.

OGUNLEYE (2006) estimated that 20 million Nigerians live in absolute poverty which represents those living on less than \$1 per day, and this situation is compounded by the neglect of agriculture and rural areas. This has perpetually contributed poverty in the nation as the agricultural sector was tactically castrated due to the discovery and exploration of oil. In his contribution, KI-MOON (2010) viewed that MDGs set time-bound targets, by which progress may be measured. Nigeria incorporated MDGs into her development agenda, as MDGs stipulated that, each nation's policies should be tailored to that country's needs within the general policy suggestions. This, however, led to the emergence of LEEMPS by the Federal Government of Nigeria in collaboration with the World Bank as a strategy towards achieving MDGs in the country.

Specifically, the deprived society, as denoted by rural communities and neglected regions, requires a more comprehensive agenda that involves community engagement to help people act on existing motivation, and includes greater recognition of frustration and anger in regional areas, towards achieving community development. Also, each country of the world has always embraced global efforts for more improved community development and redistribution of wealth through evolved mechanisms such as the Millennium Declarations and Millennium Development Goals (MDGs) and Sustainable Development Goals (SDGs) MDGs and SDGs. Specifically, the MDGs and SDGs, remain a 
global commitment to end basic human deprivation and uneven community development which continue to persist despite the various established community development programmes (UNDP, 2016).

WOLDEGIORGIS (2018) opines that community development is no doubt a meaningful and globally recognized development initiative (communitydriven) which provides control of overall development plans, processes, resources, and decision making. This is towards actualizing citizens' empowerment and improved outcomes through immediate direct and indirect effects. By implication, the direct effect engages citizens to decide directly on the allocation of resources, while its indirect effect encourages community organizations to improve citizen engagement with other local institutions within centralized government structures for good governance. Community development is however, a freedom that encompasses community participation and brings empowerment and change at all levels for the citizens with the notion of achieving substantive freedom from the multi-dimensional nature of poverty. This is aside from alleviating the problems of over-reliance on the government as the main service provider; promotion of equity, inclusiveness efficiency, better livelihood and good governance (UNDP, 2016; WOLDEGIORGIS, 2018).

In the light of this, the Federal Government of Nigeria, in conjunction with the World Bank, designed the LEEMP to address the problems of the unsustainable management of the environment, poor utilization of non-replenishable cultural resources, extreme rural and urban poverty and highly centralized governance. NNABUIKE (2014) stated that the LEEMP operates within the strategy of Community-Driven Development through the promotion of participatory decision-making, integrated multi-sectoral planning and sustainable environmental impact control among microproject communities. According to ANYEBE \& BEM (2014), the LEEMP emerged in 2004 in Nigeria through the National Economic Empowerment Strategy (NEEDS) of the Federal Government in response to development challenges in the country which had been grossly under-estimated. To this end, the National Economic Empowerment Strategy (NEEDS) was adopted at the State government level as a State Economic Empowerment Strategy (SEEDS) to suit local needs before it was finally embraced by local governments as LEEMPS. As a result, the LEEMP focuses on four key strategies of re-orientating values, reducing poverty, wealth creation and employment towards having a prosperous society. By this means, efforts are focused towards ensuring access to adequate water and sanitation, nutrition, clothing, shelter, basic education and health care. Therefore, the LEEMP activities involve sustenance of citizen empowerment, food security, employment opportunities, income generation and greater access to educational opportunities as well as skills acquisition for enhanced production capacity. ONAH ET Al. (2013) observed that the LEEMP projects were specially designed as a poverty reduction strategy and usually, aimed at enhancing the standard of living of the dwellers by empowering communities and local governments to plan collaboratively, design and implement environmentally sustainable and socially inclusive development priority projects. As a result, the problems of unsuitable management of the rural environment, poor utilisation of natural resources; extremely rural and urban poverty and highly centralized government are addressed in Nigeria by these projects.

\section{Study area}

Oyo State is located in south-western part of Nigeria, with its capital in Ibadan. It is bounded in the north by Kwara State, east by Osun State, south by Ogun State and west by Ogun State and the Republic of Benin (Fig. 1). Oyo State has thirty-three (33) Local Governemnt Areas, out of which Itesiwaju Local Government Area is a part (Fig. 2). Itesiwaju Local Government Area, with headquarters in Otu, was created in December 1996 from the old Iseyin Local Government Area. It is located in the northern part of Oyo State and approximately on longitude 36022' east of the Greenwich meridian and at a latitude $7035^{\prime}$ north of the equator (OJOAWO, 2013). It is bounded to the north by Atisbo, in the south by Kajola and Iseyin, in the east by Atiba and OyoWest in the west by Iwajowa LGAs.

The study area was divided into two parts namely the immediate benefiting communities and the non-benefiting communities for the purpose of this research work, although ten political wards namely Babaode, Igbojaiye, Ipapo I, Ipapo II, Komu, Okaka I, Okaka II, Oke-Amu, Otu I and Otu II make up this study area (Fig. 3). The immediate benefiting communities are areas with LEEMP projects and accounted for about $20 \%$ of the population of Itesiwaju LGA (study area). As an agrarian settlement, it lies within a broad savannah transition zone with an annual rainfall varing from $1,100 \mathrm{~mm}$ in the northern part to $1,200 \mathrm{~mm}$ in the southern area. The 2006 National Population Census estimated the study 
area to have a total population of 128,652 (NPC, 2007), and this was projected to be 183,427 in 2018 at a growth rate of $3 \%$, while the immediate benefiting communities of the LEEMP projects within the study area were estimated to have a population of 30,400 by the year 2018 .

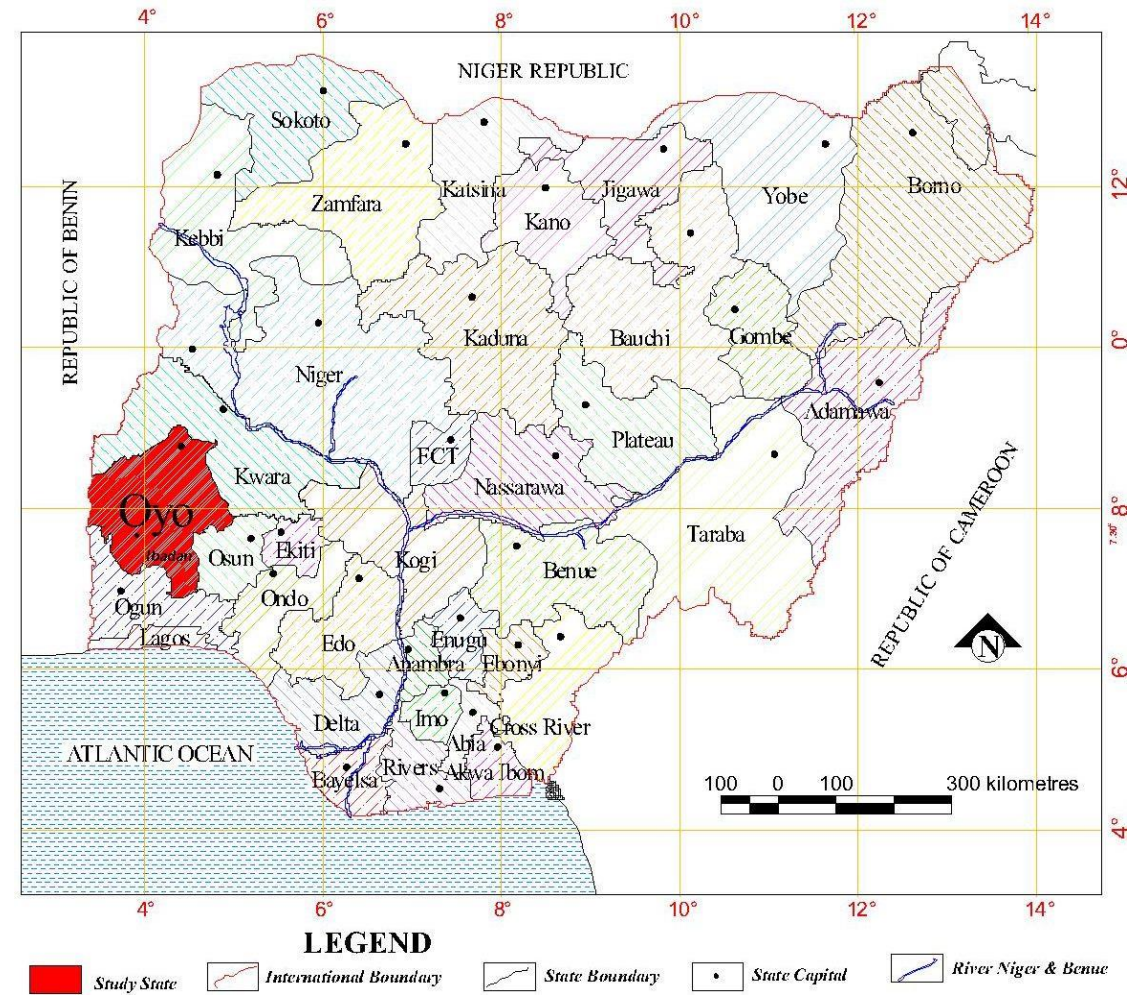

Fig. 1. Map of Nigeria showing Oyo State

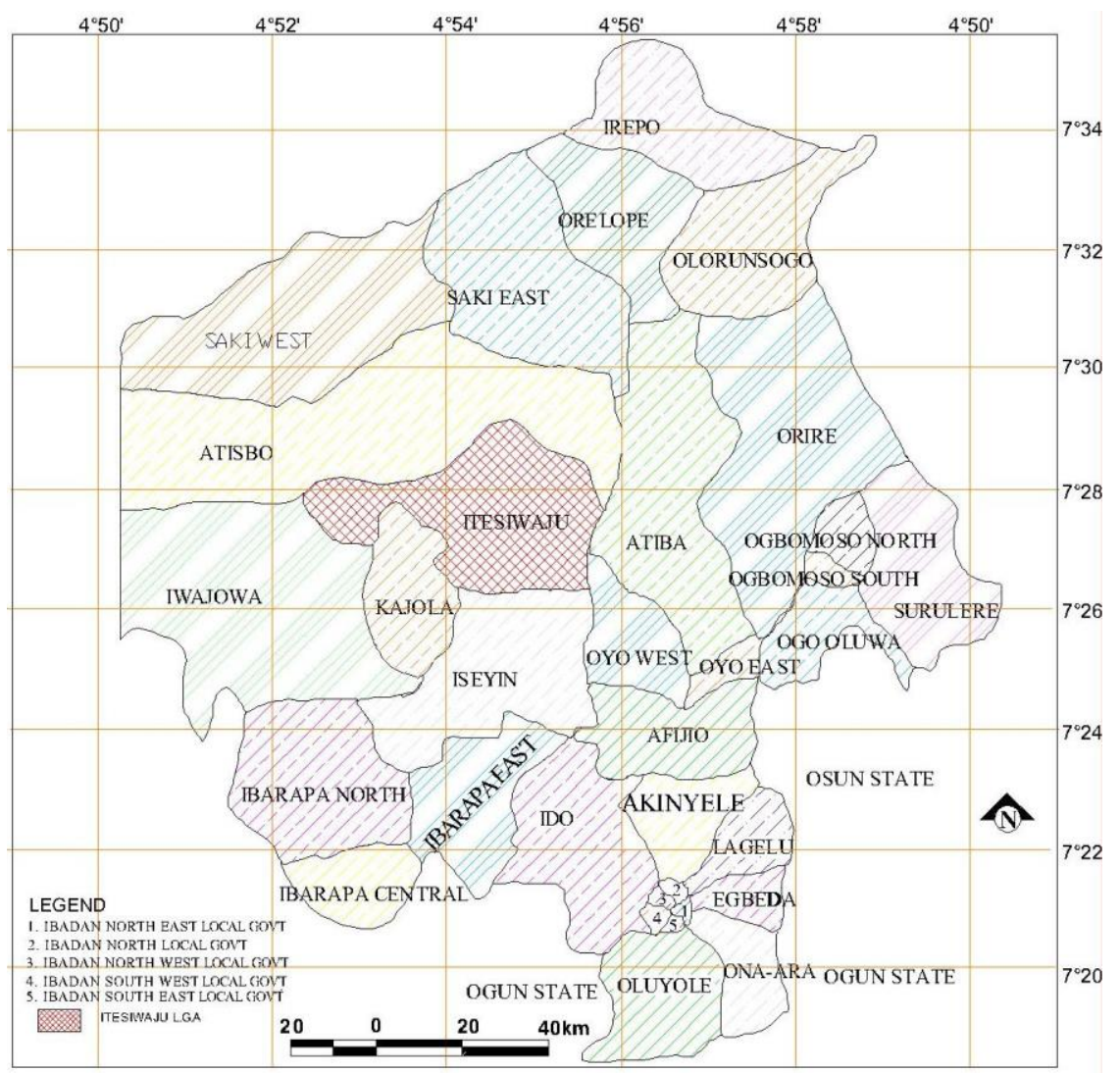

Fig. 2. Map of Oyo State showing Itesiwaju LGA 


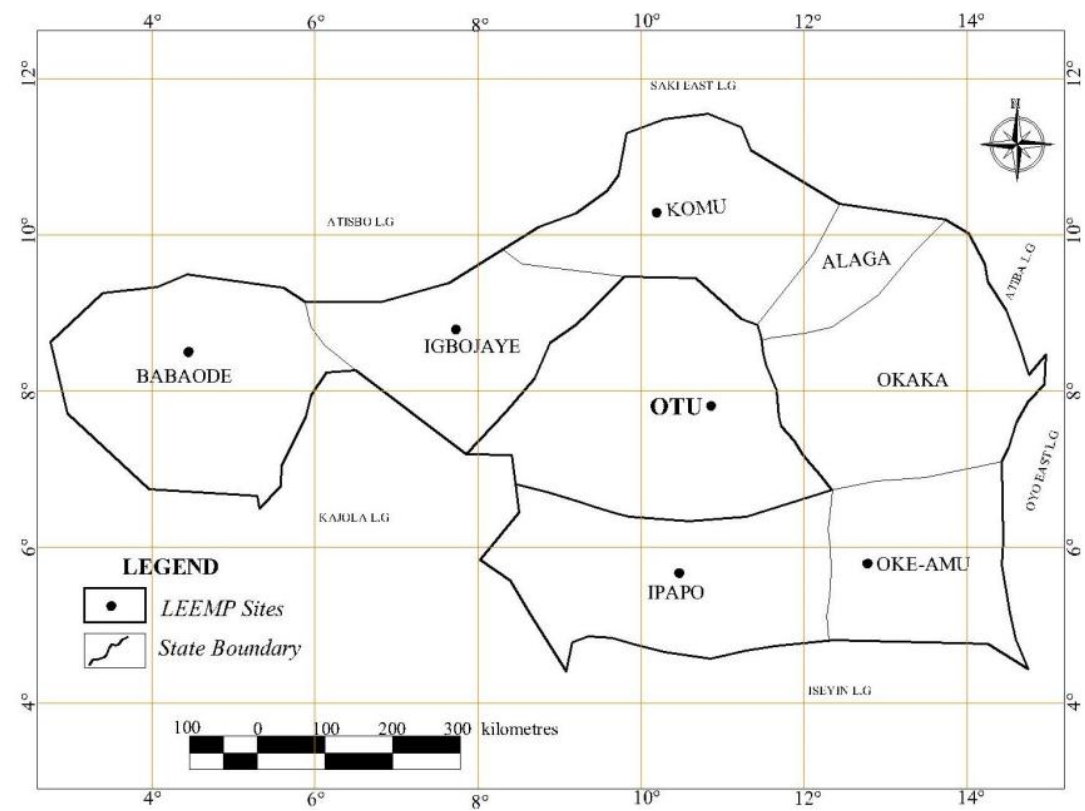

Fig. 3. Map of the Itesiwaju Local Government Area Showing the LEEMP Projects Location

\section{Materials and methods}

The data for this research were obtained through primary and secondary data sources. Primary data were majorly obtained through the use of questionnaires, administered to the residents of the benefiting communities and completed by the interview guide. The questionnaire sought for data on the residents' socio-economic attributes, notable environmental and infrastructure challenges, and the situation of existing LEEMP projects in the study area and community involvement in project development. Also, data were collected on residents' accessibility and adequacy of the facilities and projects' maintenance mechanisms. However, the structured questionnaires were in two sections (Section A and $B$ ). Section A dealt with questions on the socio-economic attributes of respondents, while section $B$ detailed questions related to the research questions and aims as identified earlier. The design of the questionnaire was based on both open and closed ended questions. Moreover, an interview guide was used to collect data from the head officials in charge of the Community and Social Development Project (CSDP) of Itesiwaju Local Government Council in Otu and the LEEMP office in Ibadan. The guide requested data on types of projects, funding, institutional capacity and challenges associated with their planning and implementation among others. The secondary data were gathered from both published and unpublished materials of related articles and journals that made up the literature which provided a contextual understanding for the study. The researchers also observed the projects directly as they visited some of the project sites during a field survey exercise. This study was first carried out during May to July, 2012 and a follow-up survey was conducted in May, 2018 to enable the researchers to obtain updated data on the situational activities, conditions and sustainability of the LEEMP projects, as well as the involvement and support of the community of the LEEMP project development and maintenance.

The population of the study area was projected as 153,617 (2012) and 183,427 (2018) people identified as residents of the Itesiwaju Local Government Area, out of which 30,400 people equivalent to $17 \%$ of the 2018 total population of the study area were residents of the immediately benefiting communities. The sampling frame and size for this research work was drawn from the population of 30,400 people within the immediate benefiting communities and the sampling technique of random sampling was applied when selecting respondents from the population pool without bias. A sample frame of $0.005 \%$ of the population of 30,400 people that characterized the immediate benefiting communities was used to draw the sample size and this percentage accounted for 152 sampled respondents as the sample size. However, 152 copies of the questionnaire were administered and used for data presentation and analysis. The justification is based on the fact that the study area is a rurally characterised location with an unpredictable population distribution pattern and engagement activities such as incessant farming, trading and commuting. The study population as 
presented, cannot be sampled entirely due to the itinerant nature of residents. Hence, the selection of a smaller proportion of the population which is usually recommended in similar situations was adopted and used to adequately select residents of the immediate benefiting communities as respondents representing the whole population without bias. For thorough validity and maximum control of the research instrument, a smaller sample size was adopted.

The collected data were analyzed using both descriptive and inferential statistics. Descriptively, the data was presented in frequency percentage tables and graphs and complemented with plates and figures to facilitate the interpretation of the collected data. A binary logistics regression model was also used to determine the result of the relevant hypothesis, (the impact of the existence of the LEEMP projects on residents' socio-economic variables). The socio-economic variables were used to measure poverty alleviation within communities in the Itesiwaju Local Government Area of Oyo State. The model was necessary to explain the prediction of factors which are likely to determine the outcome variable (existence of LEEMP projects) which is based on a set of values that was dichotomously measured as: 1 if the executed projects were perceived to be satisfactory, and 0 if otherwise. A number of socio-economic attributes for benefiting residents (respondents) were selected and tested as predictors. These factors were gender, age, household size, marital status, monthly income, occupation and educational status and were equally coded on both dichotomous $(0$ and 1) and continuous basis. All these predictor variables were modelled against the dependent variable. However, the model is presented in the following equation:

Logit $(y)=\log \{p /(1-p)\}=\beta 0+\beta_{1}{ }^{*} x_{1}+\beta_{2}{ }^{*} x_{2}+$ $\beta_{3}{ }^{*} x_{3}+\beta_{4}{ }^{*} x_{4}+\beta_{5}{ }^{*} x_{5}+\beta_{6}{ }^{*} x_{6}+\beta_{7} * x_{7}$

Where:

Logit $(\mathrm{Y})$ is the binary outcome variable indicating failure, or success, of the existence of the LEEMP projects

$\beta_{1} X_{1}+\beta_{2} X_{2}+\beta_{3} X_{3} \ldots \ldots B_{n}=$ Constant coefficients for the independent variables

$\varepsilon=$ Error term representing a proportion of the variance in the dependent variable that was unexplained by the binary logit regression equation.

$\mathrm{X}_{1}=\mathrm{X}_{\mathrm{n}}=$ independent variables/ predictors.

In other words, the level of significance of the binary logistics regression was set at $0.05 \%$ for possible acceptance, or rejection, of the hypothesis.
The Statistical Package for Social Sciences (SPSS) version 20 was used in running the analysis.

\subsection{Research limitations}

The main constraint to this study is the remoteness of the sites where the LEEMP projects were executed. Apart from the water projects at Otu, the headquarters of the Local Government Area, other project sites were located at distances of more than 50 kilometres to the local government headquarters and were poorly connected with deplorable roads. Also, the socio-economic rural characteristics of the study area delayed the timely completion of the study.

\section{Results and discussions}

\subsection{Socio-economic attributes of respondents}

It is observed from Table 1, that just over half $(52.6 \%)$ of the respondents were female, while male respondents accounted for less than half $(47.4 \%)$ of the sampled population in the area. Hence, a larger number of the female gender was served with the questionnaire and equally responded more efficiently than their male counterparts. This could be presumed to be as a result of the domestic functions of the women as well as the agrarian nature of the sampled settlements. The age distribution of respondents revealed that almost one-quarter $(24.3 \%)$ were within 31-35 years age group, slightly higher than one-fifth $(21.1 \%)$ of respondents were within the ages of 36-40 years, while slightly lower than one-fifth (14.5\%) were between 26-30 years and slightly higher than one-fifth (21\%) were those within the ages of 41-45 years. The remaining respondents who constituted less than oneeighth $(7.2 \%)$ and another slightly higher than one-eighth $(14.5 \%)$ were of ages exceeding 45 years and between 18-25 years respectively.

With respect to the marital status of respondents, it was observed that more than two-fifth (64.5\%) were married, while more than one-eighth $(15.1 \%)$ were divorced. Those widowed and single were lower than one-eighth and accounted for $10.5 \%$ and $9.9 \%$ respectively of the remaining respondents. It was deduced from this that since the majority of respondents were married that they could give reliable information on the possible effects of the LEEMP on poverty eradication in the study area. On the household size of respondents, it was observed that slightly higher than one-third $(34.9 \%)$ of respondents had 5-6 people, while more than 
one-fifth (34.2\%) had 3-4 people in their household. Almost one-fifth $(18.4 \%)$ of respondents had more than 6 people in their household, while the remaining respondents (12.5\%) had 1-2 household members. This shows that the sampled population was characterized by a large household size in excess of two people.

Table 1. Socio-economic attributes of respondents

\begin{tabular}{|c|c|c|}
\hline Variables & Frequency & Percentage \\
\hline Sex: & 72 & 47.4 \\
Fale & 80 & 52.6 \\
Fge (yrs.): 18-25 & 22 & 14.5 \\
$26-30$ & 29 & 19.1 \\
$31-35$ & 39 & 24.3 \\
$36-49$ & 32 & 21.1 \\
41-45 & 21 & 13.8 \\
>45 & 1 & 7.2 \\
Married & 15 & 9.9 \\
Divorced & 98 & 64.5 \\
Widow/widower & 23 & 15.1 \\
Marital status: single & 17 & 10.5 \\
Primary & 28 & 11.2 \\
Secondary & 45 & 18.4 \\
NCE/ND & 49 & 29.6 \\
HND/BSC & 11 & 32.2 \\
MSC/PhD & 2 & 1.2 \\
3ighest Education: none & 19 & 12.5 \\
5-6 & 52 & 34.2 \\
$>6$ & 53 & 34.9 \\
Household size: $1-2$ & 28 & 18.4 \\
Farming & 15 & 9.9 \\
Public & 79 & 52.0 \\
Personal business & 28 & 18.4 \\
Monthly income: & 30 & 19.7 \\
\#7,500-\#20,000 & 17 & 11.2 \\
\#30,001-\#30,000 & 37 & 24.3 \\
\#40,001-\#40,000 & 38 & 27.0 \\
Occupation: student & 19 & 25.0 \\
& & 12.5 \\
\hline
\end{tabular}

The occupational distribution of respondents in Table 1, revealed that more than half of respondents (52.0\%) engaged in agriculture related practices, while one-fifth $(19.7 \%)$ was involved in personal businesses/trading. The respondents who were public servants were slightly less than one-fifth $(18.4 \%)$, while those remaining who were less than one-eighth (9.9\%) were students. This illustration shows that the study area is predominantly dominated by people who are engaged in agrarian occupations such as farming, fishing, hunting and other cultivation practices. The implication of this is that the study area is a relevant location for the application of the LEEMP projects. In addition, the findings revealed that close to one-quarter of respondents (27\%) have an average monthly income of between Nigerian naira (\#) \#31,000-\#40,000 among the sampled population in the area. Also, a quarter of respondents (25\%) earned \#21,000-\#30,000 monthly. The respondents who earned more than \#50,000 each month accounted for oneeighth $(12.5 \%)$ of the sampled population, while the remaining $17 \%$ earned between $\# 7,500$ \#20,000 monthly on an average basis. This showed that the average monthly income of the vast majority of respondents was low in the study area when compared with the prevailing socioeconomic conditions of the country. Thus, the low monthly income of residents is not unconnected to the poor agrarian economy of the study area. By implication, the intervention of the World Bank in supporting Nigerian government financially on community development projects/CommunityDriven Development and programmes has significantly improved the socio-economic status (average monthly income) of the beneficiary community and its residents. Despite the fact that the sampled rural agrarians are yet to see the required support to improve their farming engagements and related activities at a large scale, it can be deduced from these findings that there is a meaningful improvement in their average monthly income (between \#31,000$\# 40,000$ ) when compared to what the civil servant can earn or receive as a monthly minimum wage of $\# 18,000$ which is less than US\$100 in Nigeria.

The results of the questionnaire also showed that slightly higher than one-fifth $(32.2 \%)$ of respondents possessed National Certificate Examination (NCE)/National Diploma (ND). Also, more than one-quarter (29.6\%) had a secondary education /technical college certificate, while those with a primary school leaving certificate were slightly less than one-fifth (18.4\%). Less than one-eighth (11.2\%) of the sampled population had no formal education, while $7.2 \%$ were those with a Higher National Diploma (HND)/B.Sc. The remaining $1.3 \%$ had higher degrees (M.Sc/PhD) among the sampled population in the study area. Therefore, it can be deduced that there was a low level of illiteracy in the area among the sampled respondents. Importantly, this literacy level was not unconnected to the various opportunities associated with the community development programmes and projects sponsored by the Word Bank and supported by the Federel Government of Nigeria. Meanwhile, the overall findings on the socio-economic attributes of the respondents of the study area showed that the LEEMP projects have meaningfully contributed to the improvement and opportunities being 
witnessed in terms of personal and community development. These findings corroborate the observation of previous related research such as OLUDIMU \& TIJANI (2009); ALABI ET AL. (2013) and LIMAN \& NGAH (2015).

\subsection{Executed LEEMP projects in the sampled communities}

The LEEMP projects in the communities are presented in Fig. 4. Importantly, this figure depicts the various percentage of projects attributed to the LEEMP in the study area. Slightly higher than one-third of respondents $(35.5 \%)$ indicated the erosion control project, while one-fifth of respondents (19.7\%) indicated flood control projects. Water-supply related projects accounted for nearly one-quarter $(24.4 \%)$ of the projects, while less than one-eighth $(8.6 \%)$ of the sampled population indicated health facility projects in their area. The respondents who indicated sanitation projects and agricultural inputs projects as the LEEMP projects in their area accounted for $7.9 \%$ and $3.9 \%$ respectively. Hence, it is observed that erosion and flood control as well as water projects ranked highest in the LEEMP projects in the study area supported by other LEEMP related programmes such as educational development and empowerment programmes. Most of the sampled areas are prone to erosion and flood related issues which causes the loss of most of their farmland, seeds and produce, and properties to environmental disasters including storms and erosion.

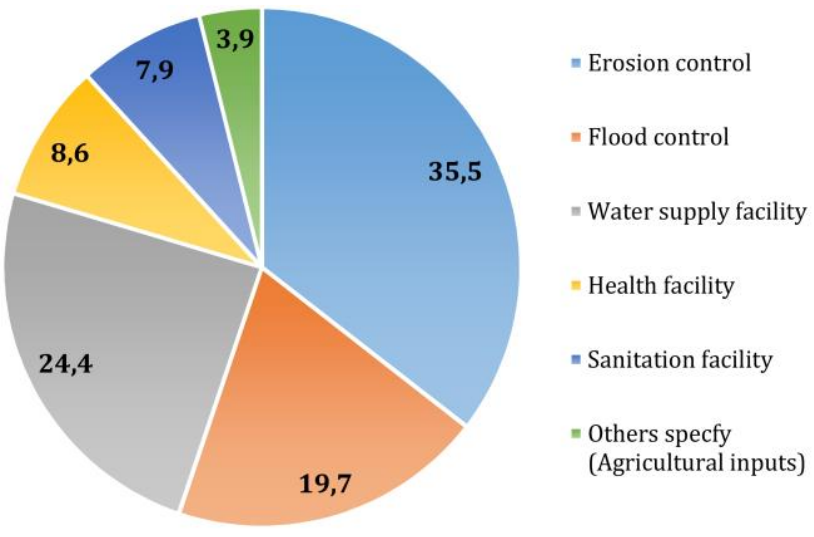

Fig. 4. LEEMP projects within the study area

The identified negative effects prompted the intervention of the LEEMP initiatives to construct four (4) drainage/erosion control channels and other related projects in the study area. Again, environmental-related projects are one of the major focuses of the LEEMP projects which were identified in the top LEEMP objectives for the sustainable management of environmental resources and maintenance of environmental and sustainable projects. These findings, however, added to, and supported, those of ONAH ET AL. (2013) and ANYEBE \& BEM (2014) who stated that the LEEMP projects not only alleviate poverty, but also specifically design formal empowerment and development strategies through salient efforts for socio-economic growth and national development.

\subsection{Notable shortcomings associated with executed LEEMP projects environmental challenges in the study area}

The sampled population gave a wide range of environmental challenges which were being faced in their respective settlements and these are shown in Fig. 5. Almost one-third of respondents (33.6\%) identified flooding as the main challenge in their area, while less than one-quarter $(23.0 \%)$ were of the view that erosion is the major environmental constraint being faced in their area. Similarly, respondents who expressed deplorable sanitation in their area were slightly higher than one-fifth (20.4\%), while more than one-eighth of them expressed a poor water supply in their area as the main challenge confronting them. Also, some respondents see unauthorized tree-felling for charcoal production (5.9\%) as a problem, while the remaining $5.0 \%$ were of the view that a shortage of electricity and health facilities, among others, are the problems faced in their area. It was deduced from these findings that flood and erosion problems were the major environmental challenges among the sampled respondents. There is an urgent need for the construction of more drainage/erosion control channels and other related projects to support the existing ones towards ameliorating these disastrous challenges and to avoid there future occurence within the study area and other settlements with similar issues. Regrettable, most of the LEEMP projects are constructed without maintenance facilities in place. As a result of poor maintenance schemes and inadequate funding, poor project costing and unencouraging financial support of some communities has led some projects to remain incomplete and/or unexecuted as noted by the officials of the LEEMP projects. This challenge, among other challenges, of poor data information and data management, poor community attitudes and poor operational logistics contributed to the major shortcomings, or challenges, facing the LEEMP projects in Nigeria. 


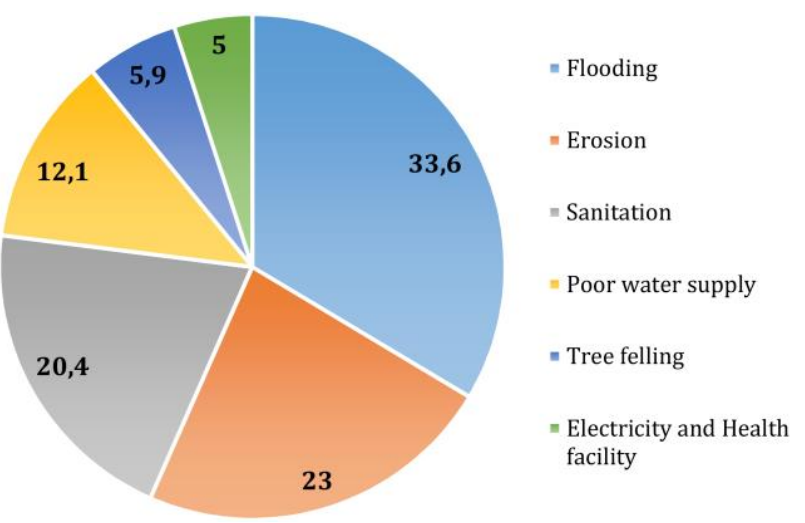

Fig. 5. Environmental challenges within the study area

\subsection{Assessment of the effectiveness of the LEEMP projects in the study area}

Table 2 shows that there were three major initiators of the LEEMP projects in the study area. More than one-quarter of respondents $(27.0 \%)$ were of the view that the community initiated most of the projects, while slightly less than onequarter $(24.3 \%$ and $3.7 \%)$ each expressed that the LEEMP and local government respectively initiated the projects. The remaining percentage (45\%) accounted for those who see both the community and the LEEMP as joint initiator of the project. In addition, more than two-fifth $(46.7 \%)$ of respondents expressed the view that the community provided land for the project, while two-thirds $(39.5 \%)$ were of the view that labour support/provision were the contribution of the community to the project in their area. The remaining 13.8\% accounted for respondents who expressed the opinion that the community provided financial support for the project in their community. The above illustration shows that the communities were actually involved in one way, or the other, in the execution of the LEEMP projects in their communities. By implication, communities, including the study area, are vitally dependent on the community-driven mechanism in maintaining the infrastructure to improve access to services, enhancing citizens' businesses and providing economic opportunities basically for socio-economic and environmental improvement and sustainability. These findings support the results of ALABI ET AL. (2013); ONAH ET AL. (2013) and ANYEBE \& BEM (2014) that the LEEMP projects, and related programmes, not only serve as a poverty reduction strategy but are also specifically designed to be community-driven projects and formal empowerment programmes and development strategies through conscious efforts of the national development plan where rural agricultural development and socioeconomic growth are manifested through salient self-community projects.

Investigations were also made on the suitability of the LEEMP projects in the study area and these responses are shown in Table 3. More than three-quarters of respondents $(77.0 \%)$ see the project as most suitable for their community, while less than one-quarter (23\%) ranked the project as suitable. In addition, nearly three quarters of respondents (74.3\%) were of the view that the community was very actively involved in the LEEMP project in their area, while slightly less than one-quarter $(23.7 \%)$ were of the view that the community was actively involved. The remaining $2 \%$ of respondents ranked their community as merely involved in community project development.

By implication, local community participation in, and control over, project implementation and maintenance, has come to be seen as an efficient and accountable mechanism for delivering good governance, long-term facilitation and strengthening of local institutions as well as enhancing the capacity of community development. The findings and implications show that community development programmes and their sustainability actions are beyond the activities stipulated by the LEEMP projects. The findings corroborate with the results from the studies of CASEY ET AL. (2013); ONAH ET AL. (2013); ANYEBE \& BEM (2014) and LIMAN \& NGAH (2015).

Table 2. Project initiator and community involvement

\begin{tabular}{|c|c|c|c|c|c|}
\hline \multicolumn{3}{|c|}{ Project initiator } & \multicolumn{3}{c|}{ Community involvement } \\
\hline Initiator & Frequency & Percentage & Involvement & Frequency & Percentage \\
\hline Community & 41 & 27 & Land provision & 71 & 46.7 \\
\hline LEEMP & 37 & 24.3 & Labour & 60 & 39.5 \\
\hline Local govt & 36 & 3.7 & Finance & 21 & 13.8 \\
\hline Community and LEEMP & 38 & 45.0 & - & - & - \\
\hline Total & 152 & 100.0 & Total & 152 & 100.0 \\
\hline
\end{tabular}


Table 3. Project suitability and extent of community involvement

\begin{tabular}{|c|c|c|c|c|c|}
\hline \multicolumn{3}{|c|}{ Project suitability } & \multicolumn{2}{c|}{ Extent of community involvement } \\
\hline Assessment & Frequency & Percentage & Ranking & Frequency & Percentage \\
\hline Very suitable & 117 & 77.0 & Very active & 113 & 74.3 \\
\hline Just suitable & 35 & 23.0 & Actively involved & 36 & 23.7 \\
\hline Not suitable & - & - & Merely involved & 3 & 2.0 \\
\hline Total & 152 & 100.0 & Total & 152 & 100.0 \\
\hline
\end{tabular}

Table 4 shows the residents' perceptions of the existing and operational conditions of the LEEMP projects in their areas. More than two-fifth (40.8\%) of respondents assessed the existing condition of the project as fair, while slightly less than two-fifths (36.8\%) assessed it to be in good condition. Also, less than one-eighth $(13.8 \%)$ saw the project in a poor and deplorable condition, while the remaining $8.6 \%$ assessed the project to be in a very good condition. Moreover, observational visits to the project sites equally confirmed the relatively good condition of most of the LEEMP projects in the study area. This may probably be as a result of the extent of involvement of the communities in the project. Additionally, three stakeholders were identified in Table 4 in the maintenance of the LEEMP projects in the study area. Findings also revealed that nearly threequarters $(66.4 \%)$ of the sampled population are of the view that the community committee are in charge of the management and maintenance of the LEEMP project in their area. Also, one-quarter (25\%) of respondents accounted for those who attributed the maintenance function of the project to the LEEMP, while the remaining $8.6 \%$ were of the view that the local government council were responsible for the maintenance of the LEEMP project in their areas. These responses of the sampled population are complementary with their earlier assertion on the extent of the community's involvement in the project.

Table 4. Existing physical conditions of the projects

\begin{tabular}{|c|c|c|c|c|c|}
\hline \multicolumn{2}{|c|}{ Physical condition of the projects } & \multicolumn{2}{c|}{ Stakeholder in project's maintenance } \\
\hline Condition & Frequency & Percentage & Stakeholders & Frequency & Percentage \\
\hline Very good & 13 & 8.6 & Local Government & 13 & 8.6 \\
\hline Good & 56 & 36.8 & LEEMP & 38 & 25.0 \\
\hline Fair & 62 & 40.8 & Community & 101 & 66.4 \\
\hline Poor & 21 & 13.8 & Other specify & - & - \\
\hline Total & 152 & 100.0 & Total & 152 & 100.0 \\
\hline
\end{tabular}

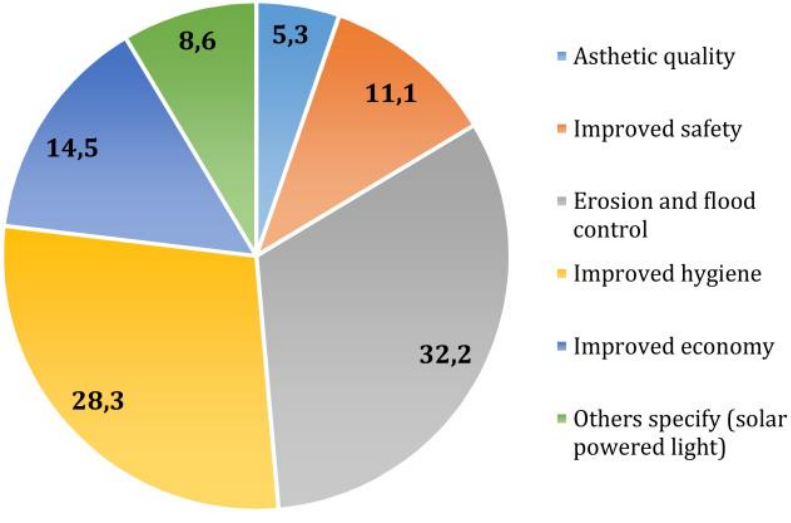

Fig. 6. Residents benefits of the LEEMP projects

Fig. 6 presents the various benefits accrued to the community in locating the LEEMP projects in their area. More than one-quarter (32.2\%) of respondents have erosion and flood control projects as their benefits. Slightly more than one-quarter (28.3\%) have improved hygiene as their benefit, while slightly more than one-eighth (14.5\%) experienced an improved economy in their area. Slightly less than one-eighth $(11.2 \%)$ have improved safety in their environment, while $5.3 \%$ of respondents also expressed enhanced aesthetic of their environment as the benefit derived from the project. The remaining $8.6 \%$ account for those respondents who have solar-powered lights as the benefits they derived from the LEEMP projects in their community. Therefore, it can be deduced from this analysis that settlements/residents have actually benefited from the LEEMP projects in the study area. 
Residents were prompted to assess the performance of the LEEMP projects in their area and their views, Table 5 shows that more than one-third (46.7\%) of respondents assessed the performance of the projects as moderate. More than one-fifth (30.9\%) respondents assessed the projects' performance as satisfactory; while more than one-eighth $(15.1 \%)$ assessed them to be very satisfactory. The remaining $7.2 \%$ said there was an unsatisfactory performance of the LEEMP projects in their area. It can be inferred from this analysis that a significant proportion of the respondents were satisfied with the performance of the projects in their area. The Table 5 also shows that, more than half $(65.8 \%)$ of the challenges confronting the LEEMP projects are shortages of funds; slightly more than a quarter of respondents (27.6\%) attributed the challenge to equipment, while $3.3 \%$ of respondents were of the view that land availability/accessibility was a challenge confronting the LEEMP projects in their area. Lastly, the remaining $3.3 \%$ of respondents said that a lack of technical know-how for the repair/maintenance of the project as the main constraint to the LEEMP projects in the area. However, it can be deduced from the responses that financial constraints are the major threat and challenge to the initiation, execution and maintenance of the LEEMP projects in the study area.

The findings on the perceptions of the projects and suggestions for their improvement are presented in Table 6. Slightly more than two-fifths of respondents (42.1\%) saw the LEEMP projects as live-enhancing projects, less than one-fifth $(17.8 \%)$ perceived them as an avenue to siphonoff public funds, while more than one-tenth (11.2\%) were of the view that the projects were a waste of scarce resources. Less than one-fifth $(13.8 \%)$ saw them as a waste of energy, while slightly less than one-tenth (9.2\%) perceived such projects as a duplication of facilities and $5.9 \%$ of respondents said they were unsuitable projects.

The numerous suggestions to tackle numerous challenges confronting the LEEMP projects are presented in Table 6. Provision for adequate funding accounts for $41.4 \%$ of the suggestions, one-quarter (38.8\%) suggested more involvement of the community in the projects conception and execution. Respondents who suggested adequate technical support, especially for the subsequent maintenance of the projects accounted for $14.5 \%$, while the remaining $5.3 \%$ suggested an all-inclusive approach.

Table 5. Performance assessment and constraints of the LEEMP Projects

\begin{tabular}{|c|c|c|c|c|c|}
\hline \multicolumn{2}{|c|}{ Residents assessment of LEEMP projects } & \multicolumn{3}{c|}{ Constraints to LEEMP projects } \\
\hline Assessment & Frequency & Percent & Constraints & Frequency & Per cent \\
\hline Very satisfactory & 23 & 15.1 & Financial & 100 & 65.8 \\
\hline Satisfactory & 47 & 30.9 & Technical & 5 & 3.3 \\
\hline Moderate & 21 & 46.7 & Land & 5 & 3.3 \\
\hline Not satisfactory & 11 & 7.2 & Equipment & 42 & 27.6 \\
\hline Total & 152 & 100.0 & Total & 152 & 100.0 \\
\hline
\end{tabular}

Table 6. Residents perceptions and suggestions for improved performance of the LEEMPs

\begin{tabular}{|c|c|c|c|c|c|}
\hline \multicolumn{2}{|c|}{ Residents perception of LEEMP projects } & \multicolumn{3}{c|}{ Residents' suggestion for improved projects } \\
\hline Perceptions & Frequency & Percentage & Suggestions & Frequency & Percentage \\
\hline Enhancement of lives & 64 & 42.1 & Adequate funding & 63 & 41.4 \\
\hline Waste of funds & 17 & 11.2 & Community involvement & 59 & 38.8 \\
\hline Waste of energy & 21 & 13.8 & Technical aid & 22 & 14.5 \\
\hline Avenue to siphon money & 27 & 17.8 & All of the above & 8 & 5.3 \\
\hline Duplication of facilities & 14 & 9.2 & Other specify & - & - \\
\hline Unsuitable projects & 9 & 5.9 & - & - & - \\
\hline Total & 152 & 100.0 & Total & 152 & 100.0 \\
\hline
\end{tabular}




\subsection{Results of interview-guide and personal} observation on the LEEMP projects and community participation in the study area

The projects executed by the LEEMP in the study area included the construction of schools (5), Markets (3), Casava production (Gari) factory (1), Health centre (2), and drilling of boreholes (6) and a deep well (1) as well as the provision of electricity transformers (2) and erosion control. The description of the typical LEEMP projects especially on erosion control as part of the LEEMP project is shown in Figs. 7 and 8. Fig. 7 and is meant to create awareness for the residents on the nature and type of LEEMP projects in the community. The need to avoid undue floods and loss of lives and properties in the area necessitated the construction of a drainage/erosion control channel in Ayedade community (Fig. 8) and in other areas with similar problems within the study area as most of the LEEMP projects are constructed without drainage facilities. Regrettably, unencouraging financial support of some communities and poor funding are major reasons

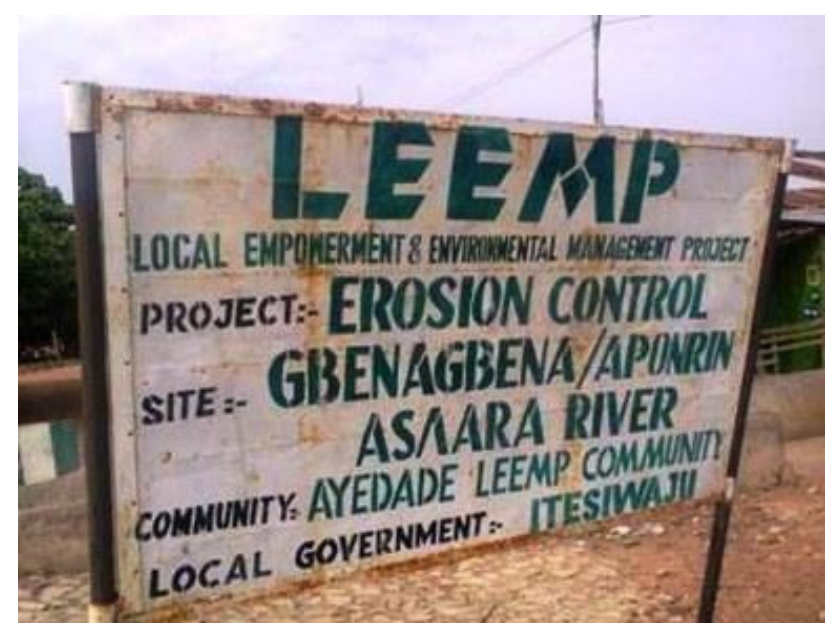

Fig. 7. Signpost of Erosion Control Project

\subsection{Hypothesis testing (impact of the existence of the LEEMP projects on the socio-economic attributes of the residents)}

Further investigations were conducted using the application of the binary logistic regression model to determine whether the socio-economic status of the respondents were being influenced by the existence of the LEEMP projects in the study area. Thus, the dependent variable (that is, the variable to be predicted) is dichotomously coded as satisfied (1) or not satisfied (0), while the independent variables (predictors) of gender, age, household size, marital status, monthly income, occupation and educational status were coded why some projects remain poorly maintained, uncompleted and neglected.

Meanwhile, most of the host communities contributed to the LEEMP projects development and maintenance more between 2012 and 2018 than in the period of the first phase of the project intervention and 2012. The community involvement in LEEMP projects development, no doubt makes most of the projects keep functioning till date and equally help significantly in community poverty alleviation. However, communities were mostly involved in the donation of land for the projects as well as in the provision of labour during the project construction including monitoring, maintenance and repair of the LEEMP project facilities during the post-construction period. Also, the state and local governments provided counterpart funds and technical support for the construction of the projects while the international agencies equally provided financial and technical support for the projects meant to improve the lives of the residents and enhance environmental sustainability in the areas.

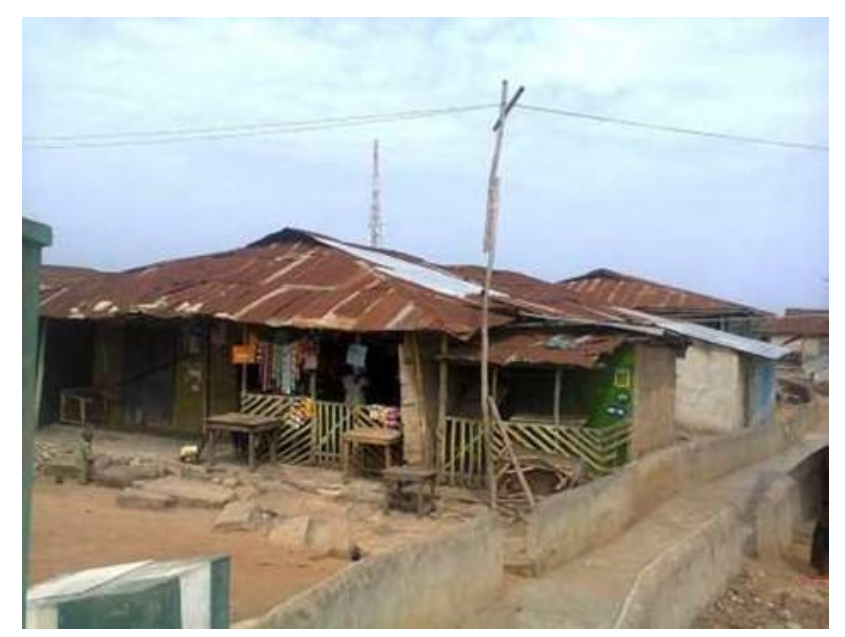

Fig. 8. Areal View of Ipapo Community

on both a dichotomous and continuous basis. However, this binary logistic regression analysis was used to model and examine the relationship between the dependent variable and independent variables as it establishes the extent of the relationship between a binary outcome variable and a group of predictor variables (see tables below).

Using the variable named above, the logistic regression equation for this study is specified as $\operatorname{logit}(y)=\log \{\mathrm{p} /(1-\mathrm{p})\}=\beta 0+\beta_{1}{ }^{*} \mathrm{x}_{1}+\beta_{2}{ }^{*} \mathrm{x}_{2}+\beta_{3}{ }^{*} \mathrm{x}_{3}+$ $\beta_{4}{ }^{*} \mathrm{x}_{4}+\beta_{5}{ }^{*} \mathrm{x}_{5}+\beta_{6}{ }^{*} \mathrm{x}_{6}+\beta_{7}{ }^{*} \mathrm{x}_{7}$

While also, logit $(\mathrm{Y})$ is the binary outcome variable indicating failure, or success, of the existence of the LEEMP projects (satisfied $=1$, while not satisfied $=0$ ). 
Table 7. Operationalization of variables

\begin{tabular}{|c|c|c|}
\hline Coding & Dependent variable & Options \\
\hline Projstat & Project satisfaction & Satisfied =1; Not satisfied $=0$ \\
\hline Coding & Independent variables & Options \\
\hline Sex & Gender of respondents (X1) $=1 ;$ Female $=0$ \\
\hline Marital & Marital status (X2) & Single $/$ divorced $/$ widow $=1 ;$ Married $=0$ \\
\hline Education & Educational status (X3) & Educated =1; Not educated =0 \\
\hline Occupation & Occupational status (X4) & Employed = ; Unemployed $/$ student $=0$ \\
\hline Age & Age of respondents (X5) & Continuous \\
\hline Income & Monthly income (X6) & Continuous \\
\hline Household & Household size (X7) & \\
\hline
\end{tabular}

Table 8. Binary Logistics Regression Analysis

\begin{tabular}{|c|c|c|c|c|c|c|c|}
\hline & \multirow{3}{*}{\multicolumn{2}{|c|}{ Observed }} & \multicolumn{5}{|c|}{ Predicted } \\
\hline & & & \multicolumn{4}{|c|}{ Project satisfaction } & \multirow{2}{*}{$\begin{array}{c}\text { Percentage } \\
\text { correct }\end{array}$} \\
\hline & & & \multirow{2}{*}{\multicolumn{2}{|c|}{$\begin{array}{c}\text { Not satisfied } \\
16\end{array}$}} & \multicolumn{2}{|c|}{ satisfied } & \\
\hline \multirow{3}{*}{ Step 1} & \multirow{2}{*}{$\begin{array}{c}\text { Project } \\
\text { satisfaction }\end{array}$} & Not satisfied & & & & & 44.4 \\
\hline & & Satisfied & \multicolumn{2}{|c|}{6} & \multicolumn{2}{|c|}{110} & 94.8 \\
\hline & \multicolumn{2}{|c|}{ Overall percentage } & & & & & 82.9 \\
\hline \multicolumn{3}{|c|}{ a. The cut value is .500} & & & & & \\
\hline \multicolumn{8}{|c|}{ Omnibus Tests of Model Coefficients } \\
\hline & & Chi-square & \multicolumn{3}{|c|}{ Df } & \multicolumn{2}{|c|}{ Sig. } \\
\hline \multirow{3}{*}{ Step 1} & Step & 49.150 & \multicolumn{3}{|c|}{7} & \multicolumn{2}{|c|}{.000} \\
\hline & Block & 49.150 & \multicolumn{3}{|c|}{7} & \multicolumn{2}{|c|}{.000} \\
\hline & Model & 49.150 & \multicolumn{3}{|c|}{7} & \multicolumn{2}{|c|}{.000} \\
\hline \multicolumn{8}{|c|}{ Model summary } \\
\hline Step & -2 Log likelihood & \multicolumn{3}{|c|}{ Cox \& Snell R Square } & \multicolumn{3}{|c|}{ Nagelkerke R Square } \\
\hline 1 & $117.263^{a}$ & \multicolumn{3}{|c|}{.276} & \multicolumn{3}{|c|}{.415} \\
\hline \multicolumn{8}{|c|}{ a. Estimation terminated at iteration number 5 because parameter estimates changed by less than .001 . } \\
\hline \multicolumn{8}{|c|}{ Variables in the Equation } \\
\hline & & $\mathrm{B}$ & S.E. & Wald & Df & Sig. & $\operatorname{Exp}(B)$ \\
\hline \multirow{8}{*}{ Step $1^{\text {a }}$} & Sex & .094 & .501 & .035 & 1 & .851 & 1.099 \\
\hline & Age & .878 & .189 & 21.571 & 1 & .000 & 2.407 \\
\hline & Marital & .023 & .314 & .005 & 1 & .941 & 1.023 \\
\hline & Household size & .705 & .301 & 5.494 & 1 & .019 & 2.025 \\
\hline & Occupation & -.105 & .273 & .148 & 1 & .701 & .900 \\
\hline & Income & -.294 & .249 & 1.401 & 1 & .033 & .692 \\
\hline & Education & .525 & .253 & 4.298 & 1 & .038 & 1.691 \\
\hline & Constant & -3.736 & 1.872 & 3.982 & 1 & .046 & .024 \\
\hline
\end{tabular}

Results from Table 8 show that 110 cases are observed to be 1 and are correctly predicted to be 1 , six (6) cases are observed to be one (1) but predicted to be zero (0), while cases that are not correctly predicted are also shown in the Table.
The overall percentage of cases that are correctly predicted by the model is $83 \%$, indicating that the model was able to classify $83 \%$ of all cases correctly. Interestingly, the model through the Chi-square result shown in Table 8 was used to 
test the overall significance of predictors (dependent variables) in the binary logistic regression model as used. The results show a Chisquare value of 49.15 and a probability of $p<0.000$.

Therefore, the dependent variable is statistically significantly predicted by the independent variables (predictors). Hence, the existence of the LEEMP projects statistically influences the socio-economic status of respondents in the study area. More so, in order to understand the extent of variables, the dependent variable can be explained by the model (the equivalent of $\mathrm{R}^{2}$ in multiple regression) will reveal the result of the Cox \& Snell $\mathrm{R}^{2}$ and Nagelkerke $\mathrm{R}$ Square value. Both methods are sometimes referred to as Pseudo $\mathrm{R}$ square values and are methods of calculating the explained variable in the model. Hence, from Table 8, the explained variation in the dependent variable based on this study model ranges from $27.6 \%$ to $41.5 \%$, respectively, indicating a moderate relationship between predictor and prediction. Furthermore, the variable in the equation Table 8 shows the contribution of each independent variable to the model and its statistical significance through the Wald Test (Wald column). The statistical significance of the test is found in the Sig. column (Table 8) and from the result age $(p=0.000)$, household size $(p=0.019)$, income $(p=0.033)$ and educational status $(p=0.038)$ added significantly to the model prediction, while gender $(\mathrm{p}=0.851)$, marital status $(\mathrm{p}=0.941)$ and occupational status $(\mathrm{p}=0.701)$ did not significantly add to the model. Hence, only four out of seven predictors best predict the model. The findings depict that a unit change, or improvement, in the execution of the LEEMP projects and programs will definitely bring about socio-economic improvement (poverty alleviation) of the residents and entire communities of the study area. By implication, the more the execution of the LEEMP projects which cut across erosion control, flood control, sanitation, water supply, power supply/electricity, agricultural inputs among other projects for rural dwellers by implementers, the higher the level of residents' standard of living and socioeconomic status of the community.

\section{Conclusion and recommendations}

In conclusion, the article analysed various projects executed under the Local Empowerment and Environmental Management Programme (LEEMP) in Itesiwaju Local Government Area of Oyo State and the implications of such projects in the enhancement of the standards of living of the residents and benefiting communities. The projects executed were laudable and had contributed towards enhancing the livability of the communities and improved the general environment of the area. By this, the socio-economic activities of the benefiting communities and residents close to such projects were improved. This study concluded that the projects of the LEEMP are laudable and reasonable as well as tools for environmental management and the socio-economic improvement of the people. Hence, such projects and programmes should be encouraged and replicated in other areas of the country. However, the sustainability of the projects calls for urgent attention to consider the deplorable nature of most of the projects. Based on the conclusion, the following recommendations are proffered.

Considering the tremendous success of the LEEMP projects in the study area, the programme should be extended to all local communities in the state and country at large to ensure even development throughout the federation as it is an active means of liberating the rural populace from poverty and distress. Also, there is a need to inject more funding and to provide adequate funding mechanisms for the programme. Thus, existing funding sources should be increased and enhanced through the involvement of more donor agencies and other non-governmental organisations. This is necessary because the provision of the infrastructure facilities and amenities are very costly and are mostly capital intensive.

The technical deficiency in the maintenance of infrastructure such as borehole and solarpowered lights should be given adequate attention. In this, extension of training programmes and workshops for selected members of the communities is essential so as to equip them to have adequate knowledge on how to maintain the facilities and carry out simple repairs and maintenance to sustain the facilities. In addition, the dumping of refuse and defecating in the erosion control channel should be strongly condemned by the community. Adequate sanctions and penalties should be put in place for those found mis-using such a facility/project to ensure their longevity. Hence, the existing legislation on environmental sanitation and waste disposal should be strictly enforced in the study area.

Finally, there is a need to put in place, accurate mechanisms to ensure the sustainability and durability of the LEEMP projects in the study area. This has become essential due to the untimely expiration of some of the projects, such 
as boreholes. If this is achieved, the durability of the projects would be enhanced for future generations to enjoy. With this, there is a need for further encouragement and involvement of the communities in the decisions of these projects that affect their well-being in their areas.

\section{References}

Alabi F.M., Ogunsesan D.K., Akanmu A.A., Ogunsesan A.S., 2013. Issues and Challenges of Poverty Eradication through Entrepreneurship Development in Nigeria Being a paper presented at the First International Conference of The Faculty of Financial Management Studies held on 7th - 9th May, 2013 at The Polytechnic, Ibadan, Ibadan.

Andy H., Andrew C. 2004. Can The Millennium Development Goals Be Attained? British Medical Journal, 329, 7462: 394-397.

Anyebe A.A., Bem V.N. 2014. An Assessment of Local Empowerment and Environment Management Project (LEEMP) in Benue and Katsina States of Nigeria. Public Administration Research, 3, 2: 1-16.

Casey K., Glennerster R., Miguel E. 2013. The GoBifo project evaluation report: Assessing the impacts of communitydriven development in Sierra Leone. International Initiative for Impact Evaluation (3ie), Report 3.

Ki-Moon B. 2010. MDGs Report accessed on October 2, 2013 at www.un.org/millenniumgoals/reports.shtml.

LEEMP/Oyo State Project Support Unit 2006. Local Empowerment and Environmental Management Programme. Progress Report on the Implementation of Community Development plans and Other Projects Activities in Oyo State.

Liman A., Ngah I. 2015. Impact Assessment of LEEMP (Local Empowerment and Environmental Management Project) in Adamawa State of Nigeria. Journal of Environmental Science and Engineering A, 4: 40-53.

National Population Commission 2007. 2006 Nigeria Provisional Census Results, Government press, Lagos.
Nnabuike O.L. 2014. Evaluation of Participatory Poverty Reduction through Water Delivery Support of Local Empowerment and Environmental Management Project (LEEMP) in Rural Southeast Nigeria. PhD Thesis, Department of Agricultural Economics, University of Nigeria, Nsukka.

Ogunleye 0.0. 2006. Challenges of Poverty Alleviation in Nigeria. The Social Sciences, 1, 3: 194-197.

Ojoawo R.O. 2013. Performance Evalution of The Local Empowerment and Environmental Management Programme in Oyo State, Nigeria, Professional Diploma Dissertation submitted to the NITP/TOPREC Examination Board Abuja, Nigeria.

Olorunfemi A.I., Ashaolu M.O. 2009. Irrigation for Food Sovereignty and Poverty Eradication. Proceedings of the 3rd International Conference of West African Society of Agricultural Engineers and 9th International Conference of Nigerian Institute of Agricultural Engineers, held at O.A.U. Ile-Ife, between January 25-29, 76-88.

Oludimu O.I., Tijani A.A. 2009. A Panacea to Rising Global Food Prices. International Journal of Multi-Research, 2, 2: 124-140.

Onah R.C., Ayogu G.I., Agboeze M.U. 2013. Sustainability of Local Empowerment and Environmental Management Project in Enugu State. Journal of Business and Management, 13, 4: 09-17.

UNDP 2006. The Millennium Development Goals: Fast Facts. UNDP.

UNDP 2016. Human development report 2016, United Nations Development Program, Oxford University Press, New York.

United Nations 2006. The Millennium Development Goals Report: 2006. Online version accessed at www.undp.org/publications/MDGReport2006.pdf on October 2, 2013.

Woldegiorgis T.B. 2018. Community Driven Development Vs Community Based Development for Practitioners and Development Actors. Community Driven Development, 1-19.

World Bank 2003. Community Driven Development: A study methodology, Operation Evaluation Department, Washington D.C.

World Bank 2006. Report on Nigeria. online version accessed on 20/01/2013 at www.worldbank.org/nigeria. 